\title{
Evaluation of Software Mediated Process Assessments for IT Service Management
}

\author{
Anup Shrestha, Aileen Cater-Steel*, Mark Toleman and Terry Rout \\ School of Management \& Enterprise, \\ University of Southern Queensland \\ Toowoomba, Australia \\ \{Anup.Shrestha, Aileen.Cater-Steel, Mark.Toleman, Terry.Rout\}@usq.edu.au
}

\begin{abstract}
IT service organisations are cognisant that continual service improvement can be achieved by conducting regular process assessments. However, such assessments are expensive and so we have developed a Decision Support System (DSS) tool which uses the international standard for process assessment ISO/IEC 15504 to offer a transparent and efficient approach. This paper provides evidence of evaluation of this software-mediated process assessment (SMPA) approach which was based on ISO/IEC 15504, ISO/IEC 20000 and the IT Infrastructure Library (ITIL®). In a usability evaluation of the online tool, participants reported largely positive experiences finding the online survey easy to use trustworthy, comfortable, generally effective, and more transparent and less costly to implement than a manual assessment. However, to engage in process improvement, human judgment, and possibly expert assessment facilitators are necessary for assessment validation and improvement, that is, a fully automated online survey that is strictly standard-based is not very useful. Further clarification of the survey questions with relevant examples, clearer answer options and having more visible goal statements on every question page were suggested.
\end{abstract}

Key words: ITSM Process Assessment, ISO/IEC 15504, evaluation, IT Service Management, Process Improvement.

\section{Introduction}

The increasing role of IT Service Management (ITSM) in facilitating business requires continual improvement of IT service processes [1]. In the current ITIL framework, Continual Service Improvement (CSI) has been proposed as an important service lifecycle phase. CSI emphasises that there should be an ongoing effort to identify opportunities for improvement in ITSM processes [2]. The CSI concept further stresses that "continual assessment" is important to identify improvement opportunities for all processes [3]. In performing CSI activities many organisations have adopted process assessment techniques that employ a systematic measurement of processes [3]. The measurement results are then used to determine the capability of each process and monitor improvements. 
An alternative to reliance on expensive consultants with proprietary process assessments is for the organisation to carry out a standard process assessment itself using software tools that may be integrated with a knowledge base of ITSM best practices. To explore this alternative, we developed a novel approach for ITSM: Software-mediated Process Assessment (SMPA). The SMPA approach is a standardsbased process assessment approach by which organisations can self-assess their processes using a DSS tool to determine process capabilities. A decision support system (DSS) tool facilitates the SMPA approach to collect data for process assessments and analyses process capabilities to recommend process improvements.

To lend objectivity and consistency to the SMPA approach, its activities are aligned with the international standard for process assessment: ISO/IEC 15504 [4]. The application of the standard in ITSM is relatively new [5]. An exemplar process assessment model for ITSM has been published as a part of the international standard for process assessment [6]. This paper illustrates results and evaluation of the SMPA approach for ITSM.

Before a detailed account of the evaluation, we briefly explain the relevance of the SMPA approach in ITSM. ITSM is a service-oriented IT management framework that advocates best practice IT service processes based on IT Infrastructure Library (ITIL $®$ ) and the international standard for ITSM ISO/IEC 20000 to ensure that IT delivers quality service to businesses. The design and architecture of the SMPA approach was previously published [7].

One of the challenges in the ITSM industry is the lack of uniformity and transparency in the way IT service processes are assessed for improvement [3]. Existing ITSM process assessment frameworks such as Tudor's IT Process Assessment [1], CMMI for Services process appraisals [8] and ITIL Assessment Services [9] use proprietary assessment models and follow indistinct assessment activities. The issue of transparency is therefore a significant hurdle in conducting an objective process assessment. The SMPA approach, being software-mediated, uses an online survey tool to collect process assessment data.

Moreover, process assessments are conducted by expert assessors by gathering a variety of objective evidence such as documents and interviews of process stakeholders [4]. Efficiency can be achieved in process assessments since a number of process assessment activities can be automated with the use of a survey with questions aligned to the standard assessment model in order to collect data from process stakeholders instead of conducting interviews. This approach can translate to significant cost savings from not using expensive assessors and consultants while enabling repeated selfassessments for IT service organisations.

While most of the existing process assessments rely on process-specific indicators that demonstrate objective evidence of process capabilities, the SMPA approach facilitates a top-down approach where assessment at each level of process capability is conducted through online surveys. In the SMPA approach, explicit questions based on the standard indicators are presented. Every question is rated using the scale: "Not", "Partially", "Largely", "Fully" and "Not Applicable" as defined in the standard. All responses for survey questions are stored in order to calculate process capability scores. Rather than the assessment team making a subjective choice of the testimony of process stakeholders, the online survey collects and objectively measures[10] feedback from the process stakeholders directly from the responses to the questions. The approach of 
asking questions directly in a web-based survey environment represents a faster and more efficient data collection method compared to assessment interviews [10]. Figure 1 shows the structure of the SMPA approach.

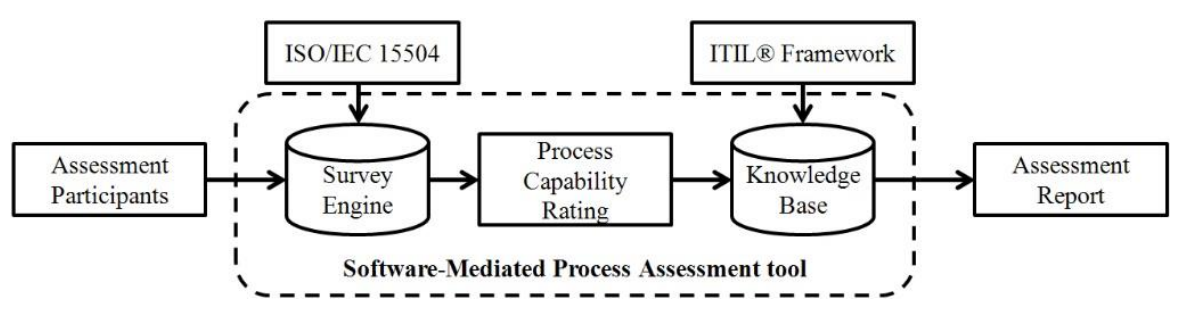

Fig. 1. Structure of SMPA approach

A literature review on ITSM process assessment is presented next to articulate the research problem. Research methodology is then discussed before a detailed account of the design and development of the SMPA architecture. Finally the conclusion section discusses the role and value of the SMPA approach that is supported by the application of ISO/IEC 15504.

\section{Literature Review}

\subsection{ITSM/SPICE/ITIL}

The literature associated with ITSM process assessment is rooted in the concept of service and quality. Existing work on IT service quality has looked to the service marketing literature and focused on adapting the SERVQUAL instrument [11] to the context of IT service. Research on IT service quality has largely focused on user satisfaction measures while there is limited research related to processes [12].

While it is a widely-agreed concept that service quality is ultimately determined by what the customer perceives, service providers should also strive to improve their processes. Organisations can conduct customer satisfaction surveys to assess the outcome of the service provision. However this is unlikely to assist service providers in improving their processes [13]. There is a need for organisations to redefine their ITSM processes to manage IT service quality [12]. Existing literature on IT service quality in terms of processes has shown a lack of research on this topic [14].

Measuring IT services is a challenging feat that requires both quantitative and qualitative metrics based on diverse service quality measures such as IT service quality, information systems quality, process quality, customer satisfaction, service value and service behaviour [12]. Few studies provide methodological guidance on an approach to determine process quality measures. A self-assessment methodology based on business excellence models and Six Sigma process improvement techniques used ITIL maturity assessments [9] for several ITIL service delivery processes. However several critical flaws in the assessment approach were reported, such as surveys with compound questions that allowed only a "yes" or "no" response [15]. 
Using ITIL processes and the international standard for process assessment ISO/IEC 15504, evidence of repeatable and objective improvement in IT service quality has been reported [7]. Extensive work on the combination of ITIL and ISO/IEC 15504 led to the development of a popular ITSM process assessment approach called Tudor's IT Process Assessment (TIPA) [1]. TIPA has been promoted as a commercial framework for ITSM process assessment [19].

ITSM process assessment approaches are discussed as best practice guidelines in the IT industry. Many of the solutions offered for ITSM process assessment are commercially available (for example, ITIL assessment services or Pink Elephant). These services can be considered as a black box since the rationale behind the assessment activities is not fully disclosed. Moreover, due to proprietary assessment processes, inconsistent outcomes from different assessment services hinder comparisons. Non-ITIL approaches such as CMMI for Services or eSCM for service providers have transparent models and methods but lack DSS support in order to conduct process assessments.

Based on the academic literature review and existing industry practices, the two key problems of lack of transparency and lack of efficiency in ITSM process assessments are apparent. Addressing transparency and efficiency are two major challenges of process assessments [3]. These challenges are taken into account in the design of the SMPA approach.

\subsection{Evaluation in Design Science Research}

Rigorous artefact evaluation primarily assesses two aspects: if the artefact causes a significant improvement; and if the artefact works in a real situation [17]. The Design Science Research (DSR) research methodology $[18,19]$ has the primary goal to develop and evaluate a new artefact. The IS design theories [20] or design principles [21] provide rigorous theoretical insights to evaluate the utility of DSR artefacts. A design theory can govern DSR based on several extant methods, such as the kernel theories [22, 23]; case studies [24] or systematic literature review [25]. By conducting a rigorous artefact evaluation, the design theories can be supported or critiqued. As a result better utility artefacts can be designed [26].

In their DSR methodology, Peffers, Tuunanen [27] suggested two steps for rigorous DSR evaluation: (1) Demonstration of how the artefact is implemented in a feasible manner; and (2) Evaluation to assess how well the artefact works.

A prominent DSR evaluation strategy should consider the "what, how, and when" aspects of evaluation design [28]. This led to the development of a DSR evaluation strategic framework which was later expanded by Venable, Pries-Heje [26]. This widely cited DSR evaluation strategic framework provides extensive evaluation design options for a DSR researcher to follow. The research methodology used to evaluate the online survey is discussed next. 


\section{Research Evaluation Methodology}

The DSR methodology is the underpinning research methodology applied for the development and evaluation of the SMPA approach. DSR methodology is outcomeoriented and thereby provides guidelines for development and evaluation of research artefacts that contribute to specific bodies of knowledge. The six DSR methodology steps [29] were followed in the research: problem identification and motivation, objectives of a solution, design and development, demonstration, evaluation, and communication.

Evaluation of the SMPA approach was organised based on the evaluation strategy advocated by Pries-Heje, Baskerville [28]. The DSR guidelines proposed by Hevner et al. [18] were also followed in an ex-post, naturalistic evaluation conducted at an IT service organisation. In order to assess if the SMPA approach has utility in a real organisation, it was essential to ensure that the survey approach was usable. Therefore, usability was determined as the key evaluation factor. The concept of usability as defined in ISO/IEC 25010 software quality in use model [30] was applied to evaluate five quality factors of the online survey: effectiveness, efficiency, usefulness, trust and comfort.

\section{Assessment results}

The assessment survey was trialled in October 2013 at the IT service department of an Australian local government authority, Toowoomba Regional Council (TRC). TRC relies on ICT tools to support the delivery of services 24 hours a day, all year round. TRC has identified a number of initiatives in its recently adopted ICT Strategic Plan [31] such as customer contact management; unified communications; eBusiness solutions for improved online accessibility of council information; spatial information services for improved web mapping services; and business architecture improvements including mobile works and self service solutions.

With the help and support from the assessment facilitators and assistance from the survey tracking functionality of the DSS tool, assessment data collection using surveys was completed by early November 2013 . The assessment report was provided to TRC in the first week of December 2013 and the evaluation performed with focus groups and interviews of TRC staff from November 2013 to January 2014. The analysis of the evaluation data was completed mid May 2014.

Three IT service processes were assessed at TRC: Problem Management (PrM), Change Management (ChM) and Configuration Management (CoM). The assessment profile generated for the three processes selected for assessment is provided in Table 1. Each attribute received 9 or 10 survey responses.

Problem Management achieved CL1 due to its rating score of "Largely" (L) at PA1.1. The other two processes were "Partially" (P) at PA1.1 suggesting that they are at CL0. The majority of the rating scores for all processes demonstrated a weak reliability score (six "Poor", 18 "Medium" and only three "High" reliability scores). This meant that survey respondents were not consistent in their answers and responses were varied. Moreover, most of the rating scores were "Partially" (P). There were two "Largely" (L), only a single "Not" (N) and none of the rating score achieved "Fully" 
(F) at any of the process attributes. This demonstrates relatively meagre process capability levels for the three processes assessed.

Table 1. Assessment Profile for Processes at TRC

\begin{tabular}{|c|c|c|c|c|c|c|c|c|c|}
\hline \multirow[b]{2}{*}{ Profile } & \multirow{2}{*}{\begin{tabular}{|l|} 
Level 1 \\
PA1.1 \\
\end{tabular}} & \multicolumn{2}{|c|}{ Level 2} & \multicolumn{2}{|c|}{ Level 3} & \multicolumn{2}{|c|}{ Level 4} & \multicolumn{2}{|c|}{ Level 5} \\
\hline & & PA2.1 & PA2.2 & PA3.1 & PA3.2 & PA4.1 & PA4.2 & PA5.1 & PA5.2 \\
\hline \multicolumn{10}{|c|}{ PROBLEM MANAGEMENT (PrM) } \\
\hline $\begin{array}{l}\text { Process } \\
\text { attribute }\end{array}$ & $\mathrm{L}$ & $\mathrm{P}$ & $\mathrm{P}$ & $\mathrm{P}$ & $\mathrm{P}$ & $\mathrm{P}$ & $\mathrm{N}$ & $\mathrm{P}$ & $\mathrm{P}$ \\
\hline Reliability & HIGH & MED & POOR & POOR & MED & MED & MED & MED & MED \\
\hline \multicolumn{10}{|c|}{\begin{tabular}{|l|} 
CHANGE MANAGEMENT (ChM) \\
\end{tabular}} \\
\hline $\begin{array}{l}\text { Process } \\
\text { attribute }\end{array}$ & $\mathrm{P}$ & $\mathrm{P}$ & $\mathrm{P}$ & $\mathrm{P}$ & L & $\mathrm{P}$ & $\mathrm{P}$ & $\mathrm{P}$ & $\mathrm{P}$ \\
\hline Reliability & MED & MED & MED & POOR & HIGH & MED & MED & MED & MED \\
\hline \multicolumn{10}{|c|}{ CONFIGURATION MANAGEMENT (CoM) } \\
\hline $\begin{array}{l}\text { Process } \\
\text { attribute }\end{array}$ & $\mathrm{P}$ & $\mathrm{P}$ & $\mathrm{P}$ & $\mathrm{P}$ & $\mathrm{P}$ & $\mathrm{P}$ & $\mathrm{P}$ & $\mathrm{P}$ & $\mathrm{P}$ \\
\hline Reliability & POOR & MED & POOR & POOR & HIGH & MED & MED & MED & MED \\
\hline
\end{tabular}

\section{Evaluation}

A focus group was organised at TRC to evaluate the usability of the online survey phase in the SMPA approach. The discussion with nine participants was recorded and later transcribed to enable qualitative data analysis. Since all participants of the focus group discussion had completed the assessment surveys, it was interesting to note the inconsistencies and variations that existed among the participants in terms of their experiences and attitudes towards the usability of the online survey.

The standard definitions were transformed to operational definitions of usability characteristics to align their meaning to specific contexts of use for the evaluation of the survey approach as shown in Table 2.

Table 2. Operational definitions of usability characteristics for evaluation of online assessment survey

\begin{tabular}{|l|l|}
\hline $\begin{array}{l}\text { Usability } \\
\text { Characteristics }\end{array}$ & Operational definition \\
\hline Effectiveness & Accuracy and transparency of the online assessment survey \\
\hline Efficiency & Time, cost and resources required for the online assessment survey \\
\hline Usefulness & $\begin{array}{l}\text { Representative and understandable assessment questions to } \\
\text { answer by using online assessment survey }\end{array}$ \\
\hline Trust & Confidence in validity of the online assessment survey \\
\hline Comfort & Ease of using online assessment survey \\
\hline
\end{tabular}


Survey participants in different roles commented on the usability of the survey approach based on their context of use. The data were analysed by reviewing focus group discussion transcripts for themes or patterns related to the five software quality in use characteristics. Maintaining privacy of the individuals who participated in this research was an ethical consideration. To protect individual identities, survey participants are referred to by each individual's most relevant process role: process manager (PM), process performer (PP) or external process stakeholder (EPS). These process roles are standard IT service roles endorsed in the ITSM community [1].

A summary of the evaluation results based on discussions and interview responses on each software quality in use factor is provided as Table 3.

Table 3. Summary of TRC online assessment survey evaluation results

\begin{tabular}{|c|c|c|}
\hline $\begin{array}{l}\text { Usability } \\
\text { characteristic }\end{array}$ & $\begin{array}{l}\text { No. of key } \\
\text { comments }\end{array}$ & Selected key comments \\
\hline Effectiveness & $\begin{array}{l}\square \times 14 \\
\text { × } \times 44 \\
\odot \times x 2\end{array}$ & $\begin{array}{l}\text { चPrM-PM1: You've got the bigger data set - more } \\
\text { reliable data. If you have an outliner, you don't skew } \\
\text { your results. People may be more honest. } \\
\text { चPrM-PP2: That whole subjective nature where it's } \\
\text { one person deciding, based on what everybody has said, } \\
\text { what the score is ... makes [manual]assessment } \\
\text { dependent on the skills of that person. Survey } \\
\text { overcomes this challenge. } \\
\text { चPrM-EPS2: I think two different versions of the } \\
\text { responses based on the group: e.g. managers say } \\
\text { something and performers say something else will be } \\
\text { very interesting - something that the software can easily } \\
\text { do. } \\
\text { 冈CoM-PM1: Some of those examples, I thought, were } \\
\text { slightly irrelevant. }\end{array}$ \\
\hline Efficiency & $\nabla \times 6$ & $\begin{array}{l}\text { VPM-PM1: the software system has the advantage of } \\
\text { giving you a really wide data set. So you can survey } 5 \\
\text { or } 50 \text { people with no added cost. Also that you don't } \\
\text { have to have them in a room. }\end{array}$ \\
\hline Usefulness & $\begin{array}{l}\bigotimes \times 15 \\
\square \times 3 \\
\odot \times 1\end{array}$ & $\begin{array}{l}\text { 冈PrM-PM1: I found some of the questions quite } \\
\text { confusing and ambiguous. } \\
\text { 冈CoM-PP4: Some of terminology used in there, } \\
\text { depending on the way the question was asked, I think } \\
\text { meant different things, to different people. } \\
\text { 冈CoM-EPS4: Answer options didn't seem to be } \\
\text { customised to the question; to the result of the question. } \\
\text { The seemed to take a generic approach. } \\
\text { चPrM-EPS2: the questions are structured well, there } \\
\text { are relevant examples and so on }\end{array}$ \\
\hline
\end{tabular}




\begin{tabular}{|l|l|l|}
\hline Trust & $\square \times 3$ & $\begin{array}{l}\text { चPrM-PM1: We could say six months after, let's do } \\
\text { that again. The logic seems valid and reliable. }\end{array}$ \\
\hline Comfort & $\begin{array}{l}\square \times 7 \\
\square \times 1\end{array}$ & $\begin{array}{l}\text { चCoM-PM1: As far as the page layout, it sort of let you } \\
\text { know how you were progressing, the colours, the font } \\
\text { and the general interface ... was excellent. }\end{array}$ \\
\hline
\end{tabular}

$\square$ indicates the usability characteristic was strongly supported in a comment

$\odot$ indicates the usability characteristic was not clear or a neutral position was taken

冈 indicates the usability characteristic was strongly opposed in a comment

In terms of the evaluation of accuracy and transparency of the online assessment survey, there were greater positive comments (70\%) in comparison to negative comments $(20 \%)$ based on the feedback from survey respondents, therefore the survey is considered effective. Process stakeholders suggested that the online survey is very objective and that it deters bias from group dynamics in the assessment process and outcome. For example:

"I think it's more objective using a software tool compared to an external assessor coming in and listening to what you say and then say 'Mmmmm I think I'll probably give that one a largely or a fully score!' "' (ChM-PMI) "And to a degree, the group dynamics, where you don't just have one person dominating the conversation [in manual assessments], whereas the survey tool gives you a say." (PrM-EPS2)

The ability to easily conduct the survey in-house with a larger number of people was one of the highlights demonstrating effectiveness of the survey approach:

"I suppose the beauty of this is that you can do these things in house. You can pick these three processes and see what comes out at level 1. Few weeks later, see what to do to get these to level 2. You've got that control over it. Rather than organising for someone to come in and do it for you." (ChM-PM1)

"We have an advantage that we are all in one geographic location. Whereas, other organisations wouldn't have the luxury of getting everyone together, if they were really dispersed. I mean, that's the way you work. The software tool is the only way to do it then." (PrM-EPS2)

However a few disadvantages of the survey approach highlighted the risk of different interpretations of the same question by survey respondents if the questions were not clear. For example:

"Survey result is likely to be much skewed because of my interpretation of the questions, as the survey went on, it changed." (PrM-PM1)

In terms of efficiency, there was overwhelming support for the online survey that it takes less time, cost and staff resources to conduct in comparison with the manual assessment. There were no negative comments about the efficiency of the online survey. Process stakeholders suggested that the survey would be a better return on investment and cost effective to operate. For example:

"the survey is probably a better return on investment because you are not taking up everyone's time all at once." (PrM-EPS2)

"I would imagine it [survey] would be cheaper to do rather than have someone [assessor] across the table for that amount of time." (PrM-PM1) 
The usefulness of the online survey in terms of clarity of the questions had largely negative comments (78\%). There were many comments regarding repetitive, ambiguous and confusing questions and the terminologies used. Since TRC undertook the assessment up to CL5 and a single process stakeholder often had multiple surveys for different roles, it must have compounded the issue. Interestingly no one complained about the application of the standard to the survey. Process stakeholders at TRC thought it was useful that the questions were strictly aligned to the standard but they were fatigued with the number of questions. For example:

"There seemed to be a fair bit of repetition in the questions." (PrM-PP2)

"I am confused. I am supposed to be looking at this from this viewpoint, now

it seems to be the other way around. How do I answer this?" (ChM-PP3)

"Lots of questions that seemed to be almost the same as the questions you did.

That was where I struggled a little bit." (CoM-PM1)

In comparison with the manual assessment, the usefulness of the online survey was negative because of the lack of support to clarify the survey questions. For example:

"With a person on the other side of the table, you could ask a question ... 'do you mean this?'. An assessor would have gone across the ambiguity of the questions. You can get that interpretation that you don't get with online survey." (PrM-PM1)

"Plus it's the interaction [in manual assessment]; it's a group of people, so you're all talking about the topic. So, you fairly quickly get it right, or get it corrected." (CoM-PMI)

However a few process stakeholders suggested that the questions are indeed structured since they are aligned to a standard and once you understand the overall structure, the survey was useful. For example:

"Once you locked into what was being asked and how it was being presented,

then it became a lot easier to answer the questions." (CoM-PP4)

The three comments regarding the trustworthiness of the online survey were all positive. Survey participants suggested that the survey is dependable and can encourage more truthful answers:

"They kind of think that they are not being watched. I can answer truthfully here because I'm not going to get in trouble - that kind of thing. It gives you a voice. I mean, you can be anonymous with a survey and not worry that your boss is sitting next to you." (PrM-PM1)

"If that's a repeatable process, you are going to get a clear measure as to whether you have improved. With the tool we can depend on it to survey in a consistent manner." (CoM-PM1)

Finally, the vast majority of comments were positive in terms of the ease of use of the online survey. Almost all survey respondents were happy with the interface and the sequencing of the questions. For example:

"The interface. I liked that and the presentation. We had just started using SharePoint and it felt very familiar. It felt 'sharepoint-ish'. It was very clean.

Some surveys you get, you are hunting - 'what would I do, where I was?' This

one was very direct and very well laid-out." (PrM-EPS2)

There was one stand-out negative comment that the convenience of the survey may be ironically a disadvantage since completing the survey is not given priority: 
"The interface and convenience though about being able to do it easily in your own time, at your own desk, it is a disadvantage because you don't have a set time that you are focussed on this. You've got distractions of people coming up, and then get side tracked on something else." (CoM-EPS4)

In summary, participants reported that they found the online survey easy to use and largely agreed that a self-assessment experience answering direct questions made the exercise more transparent and less costly to implement than a manual assessment. Moreover a tiered approach was recommended, wherein the SMPA approach could be used first to get an overall understanding of process capabilities. Afterwards, to engage in process improvement, human judgment is necessary for assessment validation and improvement based on results. Further clarification of the survey questions with relevant examples, clearer answer options and having more visible goal statements on every question page were suggested.

\section{Conclusion}

In terms of the immediate outcome of evaluation, participants reported that overall they found the online survey for assessment was trustworthy, comfortable and generally effective. Positive comments were also recorded regarding efficiency of conducting online surveys for assessments. However discussions led to a conclusion that a fully automated online survey that is strictly standard-based is not very useful. It was discussed that human input is critical for the facilitation of online assessment surveys in order to clarify survey questions with relevant examples when needed. It was also recommended that measures should be taken to provide assessment support through expert assessment facilitators, online discussion forums and/ or help screens. It was also noted that all questions do not apply well to the processes and there is a need to provide clearer answer options and better allocation of some questions to relevant process roles.

We have reported the assessment results and the evaluation of the SMPA online survey. The evaluation was based on the usability of the DSS tool that supports the SMPA approach. This paper has focused on the evaluation of one aspect of the SMPA project. Further work was also undertaken and will be disseminated regarding the evaluation of the process selection method, SMPA facilitator dashboard, assessment report, technical platform, design process, relevance to industry, alignment to ISO/IEC 15504 standard and alignment to DSR guidelines. With the current evolution of the ISO/IEC 15504 standard to the ISO/IEC 330xx family [32], modification of the survey engine and the knowledge base to reflect appropriate new process capability assessment models will be required; however there is no concern that the changes will be extreme. Further trials of the assessment survey for roll out and uptake of the SMPA approach in different organisations are planned.

The SMPA approach requires respondents to answer assessment questions based on the process indicators from the ISO/IEC 15504 PAM. A limitation of this approach is that some respondents might have unrealistic perceptions about their process activities. A more rigorous ITSM process assessment approach would involve the review of process input and output documents (work products) as instructed in the ISO/ IEC 15504 standard. Another limitation of this research is the ability of the DSS to assess only four ITSM processes. The case study in this research also has certain limitations. 
First, regarding internal validity, evaluation data were collected using qualitative research methods only. Moreover, a recognised limitation of the qualitative case study approach is the lack of ability to generalise the findings.

The SMPA approach is not intended to replace a formal conformity assessment. However organisations could use this approach when the focus is not on the precision but on a consistent approach to measure process improvements. The SMPA approach could also be used by assessors in a formal appraisal environment to collect evidence to determine process capability and maturity.

In closing, we suggest that the SMPA approach provides an opportunity for automation and transparency in the way process assessments are conducted. Beyond the discipline of service management, the SMPA approach could be applied to other domains where a process assessment model is available. Using the SMPA approach, a compliant process assessment model can be used to develop survey questions. Likewise, process improvement recommendations can be generated based on industry best practice guidelines such as ITIL $®$ in our case. With the expanding significance and reach of the ISO/IEC 15504 standard and the recently published first batch of the ISO/IEC 330xx family, the SMPA approach can be applicable for process assessments in any discipline that comprises a compliant assessment model.

Note. ITIL $®$ is a Registered Trade Mark of AXELOS Limited.

Acknowledgements: This work is supported by an Australian Research Council (ARC) Linkage grant. We thank Mr. Paul Collins of Assessment Portal Pty. Ltd. for his involvement and support in providing the platform to implement the DSS tool. We also appreciate the opportunity provided by staff at Toowoomba Regional Council to trial the SMPA and for their feedback.

\section{References}

1. Barafort, B., V. Betry, S. Cortina, M. Picard, M. St-Jean, A. Renault, and O. Valdès, ITSM Process Assessment Supporting ITIL, ed. P.R.C.H. Tudor. 2009, Zaltbommel, Netherlands: Van Haren Publishing.

2. Bernard, P., Foundations of ITIL, ed. J. Chittenden. 2012, Zaltbommel, Netherlands: Van Haren Publishing.

3. Lloyd, V., ITIL Continual Service Improvement. 2011, London, UK: The Stationery Office.

4. ISO/IEC, ISO/IEC 15504-2:2004 - Information Technology - Process Assessment - Part 2: Performing an Assessment. 2004, International Organization for Standardization: Geneva, Switzerland.

5. Mesquida, A.L., A. Mas, E. Amengual, and J.A. Calvo-Manzano, IT Service Management Process Improvement based on ISO/IEC 15504: A Systematic Review. Information and Software Technology, 2012. 54(3): p. 239-247.

6. ISO/IEC, ISO/IEC TS 15504-8:2012 - Information Technology - Process Assessment - Part 8: An Exemplar Process Assessment Model for IT Service Management. 2012, International Organization for Standardization: Geneva, Switzerland. 
7. Shrestha, A., A. Cater-Steel, M. Toleman, and T. Rout, Towards Transparent and Efficient Process Assessments for IT Service Management, in Software Process Improvement and Capability Determination. 2014, Springer International Publishing. p. 165-176.

8. CMMI, Standard CMMI® Appraisal Method for Process Improvement (SCAMPISM) A, Version 1.3: Method Definition Document. 2011, Software Engineering Institute: Carnegie Mellon University, MA, USA.

9. MacDonald, I., ITIL Process Assessment Framework. 2010, The Co-operative Financial Services: Manchester, UK.

10. Deutskens, E., K. de Ruyter, and M. Wetzels, An Assessment of Equivalence Between Online and Mail Surveys in Service Research,. Journal of Service Research, , 2006. 8(4): p. 346-355.

11. Parasuraman, A., V.A. Zeithaml, and L.L. Berry, A Conceptual Model of Service Quality and its Implications for Future Research. Journal of Marketing, 1985. 49(4): p. 41-50.

12. Lepmets, M., A. Cater-Steel, F. Gacenga, and E. Ras, Extending the IT Service Quality Measurement Framework through a Systematic Literature Review. Journal of Service Science Research, 2012. 4(1): p. 7-47.

13. Jia, R. and B.H. Reich, IT Service Climate-An Essential Managerial Tool to Improve Client Satisfaction with IT Service Quality. Information Systems Management, 2011. 28(2): p. 174-179.

14. Spath, D., W. Bauer, and C.-P. Praeg, IT Service Quality Management: Assumptions, Frameworks and Effects on Business Performance, in Quality Management for IT Services-Perspectives on Business and Process Performance. 2011, IGI Global: PA. p. 1-21.

15. Edgeman, R.L., D. Bigio, and T. Ferleman, Six Sigma and Business Excellence: Strategic and Tactical Examination of IT Service Level Management at the Office of the Chief Technology Officer of Washington, DC. Quality and Reliability Engineering International, 2005. 21(3): p. 257-273.

16. Barafort, B., B. Di Renzo, and O. Merlan. Benefits Resulting from the Combined Use of ISO/IEC 15504 with the Information Technology Infrastructure Library (ITIL). in 4th International Conference on Product Focussed Software Development and Process Improvement (PROFES). 2002: LNCS 2559, Springer-Verlag.

17. Checkland, P. and J. Scholes, Soft Systems Methodology in Practice. 1st ed. 1990, Chichester, UK: J Wiley.

18. Hevner, A.R., S.T. March, J. Park, and S. Ram, Design Science in Information Systems Research. MIS Quarterly, 2004. 28(1): p. 75-106.

19. Gregor, S. and D. Jones, The Anatomy of a Design Theory. Journal of the Association for Information Systems, 2007. 8(5): p. 312-335.

20. Pries-Heje, J. and R. Baskerville, The Design Theory Nexus. MIS Quarterly, 2008. 32(4): p. 731-755.

21. Sein, M.K., O. Henfridsson, S. Purao, M. Rossi, and R. Lindgren, Action Design Research. MIS Quarterly, 2011. 35(1): p. 37-56.

22. Iivari, J., A Paradigmatic Analysis of Information Systems As a Design Science. Scandinavian Journal of Information Systems, 2007. 19(2). 
23. Walls, J.G., G.R. Widmeyer, and O.A. El Sawy, Building an Information System Design Theory for Vigilant EIS. Information Systems Research, 1992. 3(1): p. 3659.

24. Van Aken, J.E., The Nature of Organizing Design: Both Like and Unlike Material Object Design. 2006, Eindhoven Center for Innovation Studies (ECIS).

25. Carlsson, S.A., S. Henningsson, S. Hrastinski, and C. Keller, Socio-technical IS Design Science Research: Developing Design Theory for IS Integration Management. Information Systems and e-Business Management, 2011. 9(1): p. 109-131.

26. Venable, J., J. Pries-Heje, and R. Baskerville. A Comprehensive Framework for Evaluation in Design Science Research. in Design Science Research in Information Systems (DESRIST). 2012. Las Vegas, USA.

27. Peffers, K., T. Tuunanen, M.A. Rothenberger, and S. Chatterjee, A Design Science Research Methodology for Information Systems Research. Journal of Management Information Systems, 2007. 24(3): p. 45-77.

28. Pries-Heje, J., R. Baskerville, and J.R. Venable. Strategies for Design Science Research Evaluation. in 16th European Conference on Information Systems. 2008. Galway, Ireland.

29. Peffers, K., T. Tuunanen, M.A. Rothenberger, and S. Chatterjee, A Design Science Research Methodology for Information Systems Research. Journal of Management Information Systems, 2008. 24(3): p. 45-77.

30. ISO/IEC, ISO/IEC 25010:2011 - Systems and software engineering - Systems and software Quality Requirements and Evaluation (SQuaRE) - System and software quality models. 2011, International Organisation for Standardisation: Geneva, Switzerland.

31. TRC, TRC Annual Report 2012/13. 2013, Toowoomba Regional Council: Toowoomba.

32. ISO/IEC, ISO/IEC 33001:2015 - Information technology - Process assessment Concepts and terminology. 2015, International Organisation for Standardisation: Geneva, Switzerland 